Livraisons

d'Histoire

de l'Architecture

\section{Livraisons de l'histoire de l'architecture}

$34 \mid 2017$

Le bois

\title{
Noir sur blanc
}

Jean-Michel Leniaud

\section{OpenEdition}

Journals

Édition électronique

URL : http://journals.openedition.org/lha/792

DOI : $10.4000 /$ lha.792

ISSN : 1960-5994

\section{Éditeur}

Association Livraisons d'histoire de l'architecture - LHA

Édition imprimée

Date de publication : 15 décembre 2017

Pagination : 5-6

ISSN : 1627-4970

\section{Référence électronique}

Jean-Michel Leniaud, « Noir sur blanc », Livraisons de l'histoire de l'architecture [En ligne], 34 | 2017, mis en ligne le 01 avril 2019, consulté le 24 septembre 2020. URL : http://journals.openedition.org//ha/792 ; DOI : https://doi.org/10.4000//ha.792 


\section{«NOIR SUR BLANC»}

La «filière bois » est réputée appartenir aujourd'hui au groupe des parents pauvres des industries du monde rural. Pour le comprendre on peut invoquer les forêts mal ou sous-entretenues, mal et sous-exploitées, les matières premières aussitôt coupées, aussitôt vendues en Espagne et au Portugal où, grâce à une main-d'œuvre moins coûteuse, elles sont transformées en meubles en partie destinés au marché français, l'industrie du bâtiment prisonnière des fabricants de béton. Pourtant, le bois fait l'objet des techniques les plus élaborées : après le lamellé-collé dont l'origine remonte à Philibert Delorme mais dont le procédé est perfectionné en 1890 par un charpentier allemand, Otto Hetzer, puis breveté de 1906 à 1907, le bois lamellé-croisé (cross laminated timber) offre des portées considérables (vingt mètres de long sur quatre mètres de large). On le trouve employé depuis la seconde moitié $\mathrm{du} \mathrm{XX}$ siècle dans des édifices majeurs : à l'église Stella-Matutina à Saint-Cloud comme au Palais de l'Europe à Strasbourg. Il fait l'objet des sollicitudes des pouvoirs publics qui incitent à l'employer dans la construction privée : l'Exposition internationale du bois organisée à Lyon en donne, en 1951, un bel exemple, mais aussi l'exposition coloniale internationale de Paris en 1931, celle de 1937 et toutes les expositions universelles qui suivirent depuis 1950. Le bois, cependant, suscite aussi des réactions hostiles: l'emploi massif de bois exotiques, aux marches qui conduisent à la Bibliothèque nationale de France, par exemple, ne peut qu'être mis en rapport avec la terrible déforestation de l'Amazonie et de l'Afrique équatoriale. De l'autre côté du monde, la destruction par l'État polonais de la forêt de Bialowieza, forêt naturelle parmi les mieux conservées d'Europe, suscite le courroux de la Commission européenne.

Le bois fait entrer la construction dans l'ordre du mystère : l'art du charpentier, l'art du trait, le savoir intuitif de celui qui sait «s'orienter », qui a fait l'objet d'une inscription en 2009 sur la liste du patrimoine culturel de l'humanité, tourne l'architecture du côté des mythes fondateurs. Ce n'est pas un hasard si, en plein Second Empire, au temps des ingénieurs saint-simoniens, d'ailleurs non moins mystiques, le charpentier Bellu place les flèches de la Sainte-Chapelle et de Notre-Dame de Paris dont ses compagnons sont les auteurs collectifs, sous l'invocation du Grand Architecte de l'Univers. Mais avec ses savoir-faire plus ou moins secrets qui se transmettent de bouche de compagnon à oreille d'apprenti, avant qu'ils ne donnent le contenu de savants traités, tel celui de Nicolas Fourneau (1767), le travail du charpentier place le travail technique sous l'angle d'une réflexion intellectuelle approfondie : il en faut pour concevoir un «trait de Jupiter » qui vienne raccorder deux poutres de façon qu'en n'en formant qu'une, elles assument un rôle porteur. Reste que la science, comme il arrive toujours dans la sphère du savoir faire, ne 
peut pas se substituer à l'intuition, à la mémoire de l'œil et des mains, au métier quotidien : "L'Orient vaut le trait».

Dans le concret, il faut au départ posséder la pratique et la science du forestier : il sait planter les arbres et les laisser croître, les choisir et les couper au bon moment. On connaît l'anecdote racontée par l'abbé Suger lorsqu'il se rend personnellement choisir sur place les arbres pour son abbatiale de Saint-Denis : en dépit du scepticisme moqueur des forestiers, il finit par trouver dans la forêt royale de l'Yveline les douze grands arbres dont il a besoin. Il faut encore organiser le mode d'acheminement des fûts dont l'encombrement est sans commune mesure avec celui des blocs de pierre extraits de la carrière ; savoir les laisser vieillir avant emploi, c'est-à-dire consentir à les stocker longtemps à ses risques et à ses frais. Il faut encore les débiter en fonction des capacités de chaque tronc, mais aussi des besoins de l'activité du bâtiment. Il faut encore savoir les acheter en évitant les vices cachés : les insuffisances de la marine royale au XVIII ${ }^{\mathrm{e}}$ siècle face à la marine britannique sont imputables souvent à des bois mal choisis ou payés insuffisamment cher. Quant au Journal de Pierre-François-Léonard Fontaine, il fourmille de récriminations à l'encontre d'entrepreneurs qui mettent en œuvre des bois qui, mal débarrassés de leur sève, deviennent rapidement véreux. On croise aussi dans les mêmes pages un milieu particulièrement turbulent et prompt à la grève au point qu'il contribua à sa propre disparition : la charpenterie métallique était plus fiable.

$\mathrm{Au}$ reste, la poutraison industrielle répondait à la rationalisation du chantier en offrant un matériel préfabriqué et dûment normé. Le bois, en dépit des trésors d'intelligence qu'impliquait sa mise en œuvre, ne permettait pas la normalisation de la construction. Si on met à part le chalet suisse avec ce qu'il supposait de préfabrication, de démontabilité et d'aptitude à l'industrialisation et à l'exportation, il fallut attendre l'invention du lamellé-collé et l'emploi des colles d'assemblage adéquates pour que le défi que lançait l'architecture normalisée pût être relevé. Jean Prouvé avec son pan de bois industriel, le moins connu Jean-Pierre Watel avec son prototype de maison en bois en donnent l'exemple.

Aujourd'hui l'avenir du bois dans l'architecture et dans la construction reste incertain. L'œil ne semble pas encore las des assemblages de verre, de métal et de béton, les économistes du bâtiment ne semblent pas émus outre mesure des dépenses énergétiques qu'ils occasionnent, les donneurs d'ouvrages n'incluent pas le bois dans leurs consignes de programmation lors des concours qu'ils lancent, l'imagination plastique des architectes y trouve rarement son aliment. Pourtant, jamais ce matériau n'a offert autant de ressources et répondu à autant d'enjeux : structurels, écologiques, symboliques. Le retour généralisé du bois dans l'architecture, une utopie? L'histoire du matériau naturel n'est certainement pas parvenue à son point final.

J.-M. L. 